\title{
Vertebral Fracture
}

National Cancer Institute

\section{Source}

National Cancer Institute. Vertebral Fracture. NCI Thesaurus. Code C80516.

Traumatic or pathological injury to the spine in which the continuity of a vertebral bone is broken. Symptoms include back pain and difficulty bending and twisting. 